\title{
BMJ open \\ A comparison of Australian rural and metropolitan cardiovascular risk and mortality: the Greater Green Triangle and North West Adelaide population
} surveys

To cite: Tideman $P$,

Taylor AW, Janus E, et al. A comparison of Australian rural and metropolitan cardiovascular risk and mortality: the Greater Green Triangle and North West Adelaide population surveys. BMJ Open 2013;3:e003203. doi:10.1136/bmjopen-2013003203

- Prepublication history for this paper is available online. To view these files please visit the journal online (http://dx.doi.org/10.1136/ bmjopen-2013-003203).

Received 10 May 2013 Revised 30 June 2013 Accepted 16 July 2013
For numbered affiliations see end of article.

\section{Correspondence to} Prof James A Dunbar; director@greaterhealth.org

\section{ABSTRACT}

Objectives: Cardiovascular (CVD) mortality disparities between rural/regional and urban-dwelling residents of Australia are persistent. Unavailability of biomedical CVD risk factor data has, until now, limited efforts to understand the causes of the disparity. This study aimed to further investigate such disparities.

Design: Comparison of (1) CVD risk measures between a regional (Greater Green Triangle Risk Factor Study (GGT RFS, cross-sectional study, 2004-2006) and an urban population (North West Adelaide Health Study (NWAHS, longitudinal cohort study, 20042006); (2) Australian Bureau of Statistics (ABS) CVD mortality rates between these and other Australian regions; and (3) ABS CVD mortality rates by an arealevel indicator of socioeconomic status, the Index of Relative Socioeconomic Disadvantage (IRSD).

Setting: Greater Green Triangle (GGT, Limestone Coast, Wimmera and Corangamite Shires) of SouthWestern Victoria and North-West Adelaide (NWA). Participants: 1563 GGT RFS and 3036 NWAHS stage 2 participants (aged 25-74) provided some information (self-administered questionnaire $+/-$ anthropometric and biomedical measurements).

\section{Primary and secondary outcome measures:} Age-group specific measures of absolute CVD risk, ABS CVD mortality rates by study group and Australian Standard Geographical Classification (ASGC) region.

Results: Few significant differences in CVD risk between the study regions, with absolute CVD risk ranging from approximately $5 \%$ to $30 \%$ in the $35-39$ and 70-74 age groups, respectively. Similar mean 2003-2007 (crude) mortality rates in GGT (98, 95\% $\mathrm{Cl} 87$ to 111$)$, NWA (103, 95\% Cl 96 to 110$)$ and regional Australia (92, $95 \% \mathrm{Cl} 91$ to 94$)$. NWA mortality rates exceeded that of other city areas (70, 95\% Cl 69 to 71$)$. Lower measures of socioeconomic status were associated with worse CVD outcomes regardless of geographic location. Conclusions: Metropolitan areas do not always have better CVD risk factor profiles and outcomes than rural/regional areas. Needs assessments are required

\section{ARTICLE SUMMARY}

Article focus

- The study aim was to more objectively understand causes of geographical cardiovascular disease (CVD) mortality disparities in Australia by; (1) comparing measures of CVD risk (objective and self-reported data) between a rural population (Greater Green Triangle, GGT) and an urban population (North West Adelaide, (NWA)).

- (2) Comparing CVD mortality rates among GGT and NWA and other areas Australia-wide.

- (3) Describing the relationship between socioeconomic status (SES) and CVD mortality rates.

Key messages

- This study supports existing evidence of a social gradient in cardiovascular health.

- This study provides evidence to reject the assertion that location of residence in Australia necessarily results in poorer cardiovascular health.

Strengths and limitations of this study

- This is the first comparison of both self-report and biomedical data from a wholly rural/regional Australian population study with a metropolitan population study.

- Determinants of cardiovascular health are contextual, and the study populations will not necessarily represent rural and urban populations more generally in Australia.

- Direct analysis of associations between risk factors, SES and CVD mortality in the sample data sets was not possible due to the crosssectional rather than longitudinal design of the two population-based risk factor studies and other methodological differences in sampling and data collection.

for different settings to elucidate relative contributions of the multiple determinants of risk and appropriate cardiac healthcare strategies to improve outcomes. 


\section{INTRODUCTION}

Place of residence is an important determinant of health. In many settings worldwide, there is an underinvestment in health-promoting infrastructure and opportunities in rural communities leading to urban migration and geographical health inequalities. ${ }^{1}$ Australia is a highly urbanised country with approximately two-thirds of the population living in major cities. ${ }^{2}$ Well-documented health inequalities exist between regional and remote versus urban settings. In the former, life expectancy is $1-7$ years lower and decreases with increasing remoteness. ${ }^{3}$ An approximate $10 \%$ difference in all-cause mortality rates has been consistently documented between major cities and the rest of Australia. ${ }^{4}$

As in many other countries, cardiovascular disease (CVD) - principally ischaemic heart disease (IHD) and cerebrovascular disease-is the largest contributor to overall mortality in Australia. ${ }^{5}$ Coronary heart disease and 'other' circulatory diseases are the two largest contributors to the excess mortality observed outside major city areas $(20 \%$ and $17 \%$ of the excess mortality between 2002 and 2004). ${ }^{4}$ Measuring contributions of biological and behavioural risk factors, social and economic determinants, access to quality care and broader politicostructural influences on CVD health outcomes in Australia has proved difficult, especially in rural areas.

A recent Australian Institute of Health and Welfare report found that prevalence of key CVD risk factors increases with increasing remoteness from major city areas. ${ }^{6}$ Such self-report data, however, has limitations. Despite the obvious need for more objectively measured population data, very little risk factor data in the form of biomedical measurements are available for comparative studies among remote, regional and urban areas. Better evidence is required to develop strategies to address inequalities.

This article reports on absolute CVD risk from two population biomedical surveys covering a regional area (Greater Green Triangle, GGT) and metropolitan area (North-west Adelaide, NWA), along with CVD mortality rates from corresponding regions drawn from national data records. To our knowledge, it is the only comparative study of measured biomedical risk factors and mortality data between specifically regional and urban populations in Australia to date.

The aim of the study was to more objectively understand causes of geographical CVD mortality disparities by (1) comparing measures of CVD risk (objective and self-reported data) between GGT and NWA, (2) comparing CVD mortality rates between GGT and NWA and other areas Australia-wide and (3) describing the relationship between socioeconomic status (SES) and CVD mortality rates.

We hypothesised that (1) higher mortality rates would be observed in GGT than NWA and that (2) these would be influenced by worse CVD risk factor profiles in the former.

\section{METHODS}

\section{Study design}

This study compared CVD risk factor data (individual as well as absolute 5-year CVD risk) from two studies-a regional cross-sectional population survey and an urban longitudinal cohort—conducted over a similar time period. In addition, Australian Bureau of Statistics (ABS) CVD mortality rates in different geographical locations were compared and the relationship between mortality and SES explored.

\section{Population and sample}

\section{Comparing measures of CVD risk}

Details of the methodology of both studies have been published elsewhere. ${ }^{7-11}$ Discussed below is a brief summary of the setting, population and sample.

\section{Greater Green Triangle Risk Factor Study}

GGT encompasses a population of 225000 in south-east South Australia and south-west Victoria. The Greater Green Triangle Risk Factor Study (GGT RFS) comprised three cross-sectional population surveys (Limestone Coast, Corangamite and Wimmera Shire Risk Factor Surveys) conducted between 2004 and 2006. In total, 1563 randomly selected persons aged 25-74 provided some information (self-administered questionnaire +/ attendance at survey site for anthropometric and biomedical measurements including fasting venous blood specimens for lipids and glucose). Socioeconomic indicators of GGT RFS participants compared with available population statistics indicated that the survey population closely represented the overall GGT population. ${ }^{7}$

\section{North West Adelaide Health Study}

Adelaide, the capital of South Australia, has a population of 1.18 million. ${ }^{12}$ The northern and western suburbs, stretching from Glenelg to Gawler, encompass approximately half of Adelaide's population and one-third of the South Australian population. The North West Adelaide Health Study (NWAHS) is a largely representative cohort of over 4000 randomly selected adults aged more than 18 years recruited from NWA between 2000 and 2003 (stage 1) returning between 2004 and 2006 (stage 2). Each stage included a telephone survey, self-administered questionnaire and anthropometric and biomedical examination. NWAHS stage 1 participants had some demographic differences but no health risk behaviour differences compared with ABS 2006 census data and South Australian Surveillance and Monitoring System data. ${ }^{13}$

In this study, participants aged 25-74 were selected to make the age range of both populations comparable. From NWAHS, only stage 2 participants were selected and 3036 provided information. 
Sources and measures

Comparing measures of CVD risk

Demographic characteristics have been reported previously and are presented in table $1 .{ }^{14} \mathrm{~A}$ comprehensive examination of methodologies and questionnaire wordings of both studies had been undertaken to ensure that variables were comparable. Some aspects could not be compared due to differences in questions used such a household income, levels of alcohol consumption, physical activity and quality of life. GGT RFS participant age was calculated from the survey date after assuming each individual was born on June 30 in their given year of birth. NWAHS participant age was calculated from their date of birth and clinic appointment date and truncated.

Five-year absolute CVD risk, defined as ischaemic heart disease (IHD) and stroke collectively, was calculated using the Framingham equation which is used to make Australian cardiovascular event-risk charts. ${ }^{15}$ Calculation of CVD risk was restricted to participants aged 35-74 years who reported no history of heart attack or stroke. Biomedical measurements required for use of the equation were available from both studies. Smoking status was determined by self-report. Diabetes was defined as having a survey fasting plasma glucose level of $7 \mathrm{mmol} / \mathrm{L}$ or above and/or having self-reported diabetes. As the questionnaire

Table 1 Demographic characteristics of participants by location

\begin{tabular}{|c|c|c|c|c|c|c|}
\hline & \multicolumn{3}{|c|}{ NWAHS } & \multicolumn{3}{|c|}{ GGT RFS } \\
\hline & $\mathbf{n}$ & $\begin{array}{l}\text { Per } \\
\text { cent }\end{array}$ & $95 \% \mathrm{Cl}$ & $\mathbf{n}$ & $\begin{array}{l}\text { Per } \\
\text { cent }\end{array}$ & $95 \% \mathrm{Cl}$ \\
\hline \multicolumn{7}{|l|}{ Demographics } \\
\hline \multicolumn{7}{|l|}{ Sex } \\
\hline Male & 1437 & 50.2 & (48.0 to 52.4$)$ & 714 & 50.2 & (46.9 to 53.5$)$ \\
\hline Female & 1426 & 49.8 & (47.6 to 52.0$)$ & 708 & 49.8 & (46.5 to 53.1$)$ \\
\hline \multicolumn{7}{|l|}{ Age (years) } \\
\hline $25-44$ & 1412 & 49.3 & (47.1 to 51.6$)$ & 599 & 42.1 & $(38.6 \text { to } 45.7)^{*}$ \\
\hline $45-54$ & 620 & 21.6 & (20.1 to 23.3 ) & 350 & 24.6 & $(22.3 \text { to } 27.1)^{*}$ \\
\hline $55-64$ & 477 & 16.7 & (15.4 to 18.0$)$ & 277 & 19.5 & $(17.6 \text { to } 21.5)^{*}$ \\
\hline $65-74$ & 355 & 12.4 & (11.3 to 13.6$)$ & 196 & 13.8 & (12.4 to 15.3$)$ \\
\hline \multicolumn{7}{|l|}{ Aboriginal or Torres Strait islander } \\
\hline No & 2785 & 97.3 & (96.5 to 97.8$)$ & 1405 & 98.8 & $(98.1 \text { to } 99.3)^{\star}$ \\
\hline Yes & 13 & 0.4 & $(0.2$ to 0.8$)$ & 8 & 0.6 & $(0.3$ to 1.1$)$ \\
\hline \multicolumn{7}{|l|}{ Country of birth } \\
\hline Australia or New Zealand & 2064 & 72.1 & (70.2 to 73.9$)$ & 1339 & 94.1 & $(92.8 \text { to } 95.2)^{*}$ \\
\hline UK or Ireland & 451 & 15.8 & (14.4 to 17.3$)$ & 27 & 1.9 & $(1.4 \text { to } 2.6)^{\star}$ \\
\hline Europe & 223 & 7.8 & (6.8 to 8.9$)$ & 26 & 1.8 & $(1.4 \text { to } 2.5)^{*}$ \\
\hline Other & 116 & 4.0 & (3.2 to 5.1$)$ & 28 & 2.0 & $(1.3 \text { to } 3.0)^{\star}$ \\
\hline \multicolumn{7}{|l|}{ Highest level of education obtained } \\
\hline Secondary school or lower & 1568 & 57.9 & (55.5 to 60.3$)$ & 920 & 64.7 & $(61.4 \text { to } 67.9)^{*}$ \\
\hline $\begin{array}{l}\text { Trade/Apprenticeship/Certificate/Diploma/Vocational } \\
\text { training (TAFE/VET) }\end{array}$ & 651 & 24.1 & (22.0 to 26.3$)$ & 254 & 17.9 & $(15.3 \text { to } 20.8)^{\star}$ \\
\hline Bachelor degree or higher & 460 & 17.0 & $(15.1$ to 19.1$)$ & 229 & 16.1 & (13.7 to 18.8$)$ \\
\hline \multicolumn{7}{|l|}{ Marital status } \\
\hline Married or living with a partner & 1988 & 73.5 & (71.2 to 75.6$)$ & 1198 & 84.2 & $(81.8 \text { to } 86.4)^{\star}$ \\
\hline Separated or divorced & 252 & 9.3 & (8.3 to 10.5$)$ & 86 & 6.0 & $(4.8 \text { to } 7.6)^{*}$ \\
\hline Widowed & 77 & 2.9 & $(2.4$ to 3.4$)$ & 46 & 3.2 & (2.6 to 4.0$)$ \\
\hline Never married (single) & 381 & 14.1 & (12.1 to 16.3$)$ & 91 & 6.4 & $(4.8 \text { to } 8.5)^{\star}$ \\
\hline \multicolumn{7}{|l|}{ Work status } \\
\hline Full-time employed & 1352 & 50.0 & (47.5 to 52.4$)$ & 680 & 47.8 & (44.5 to 51.1$)$ \\
\hline Part time/Casual employment & 514 & 19.0 & (17.2 to 20.9$)$ & 327 & 23.0 & $(20.2 \text { to } 26.0)^{*}$ \\
\hline Unemployed & 58 & 2.2 & (1.6 to 2.9$)$ & 43 & 3.0 & (2.2 to 4.3 ) \\
\hline Home duties & 304 & 11.2 & (9.9 to 12.7$)$ & 126 & 8.8 & $(7.1 \text { to } 11.0)^{\star}$ \\
\hline Retired & 378 & 14.0 & (12.8 to 15.2$)$ & 209 & 14.7 & (13.1 to 16.4$)$ \\
\hline Student & 27 & 1.0 & (0.6 to 1.8$)$ & 3 & 0.2 & $(0.06$ to 0.7$) \dagger$ \\
\hline Other & 64 & 2.4 & (1.8 to 3.0$)$ & 11 & 0.8 & $(0.4 \text { to } 1.6)^{*}$ \\
\hline Total & 2864 & 100 & & 1422 & 100 & \\
\hline \multicolumn{7}{|c|}{$\begin{array}{l}\text { The weighting of the data can result in rounding discrepancies or totals not adding. } \\
\text { *Statistically significantly different }\left(\chi^{2} \text { test, } p<0.05\right) \text { GGT RFS compared with NWAHS. } \\
\text { Authors on this paper are the rights-holders of this previously published table and have given their permission to include it here. } \\
\text { tInsufficient numbers for a statistical test. } \\
\text { NWAHS, North West Adelaide Health Study; GGT RFS,Greater Green Triangle Risk Factor Study. }\end{array}$} \\
\hline
\end{tabular}


used in GGT RFS asked whether a participant had ever been diagnosed with impaired glucose tolerance, participants who responded positively were considered to have diabetes. As no electrocardiogram information was available for any participants, the left ventricular hypertrophy variable was excluded from the risk calculation.

\section{Comparing CVD mortality outcomes}

Mortality rates were obtained using 2003-2007 ABS mortality (numerator) and estimated residential population (ERP, denominator) data according to relevant 2006 statistical local area (SLA) codes. ${ }^{16}{ }^{17}$ ABS Australian Standard Geographical Classification System (ASGC) for remoteness areas uses categories major cities, inner regional, outer regional, remote and very remote ${ }^{17}$ Thirty-one SLA codes representing GGT $(n=13)$ and NWA $(n=18)$ were used. According to ASGC all GGT SLAs were classified as inner or outer regional and all NWA SLAs as major city areas. In this comparative study, 'inner and outer regional' areas consisted of all areas in this ASGC category combined, but excluded GGT SLAs. 'Remote and very remote' areas represented all such ASGC areas combined. 'Major cities' included all Australian cities classified as such by the ASGC, excluding NWA SLAs. Mortality information was extracted according to predefined International Classification of Diseases (ICD) 10 codes. $^{5}$ ICD 10 codes I20-I25 and I61-I64 were used to make up the category IHD and Stroke.

\section{Relationship between SES and CVD mortality rates}

SES was measured using index of relative socioeconomic disadvantage (IRSD). IRSD is one of the four ABS socioeconomic indexes for areas (SEIFA), which are areabased summary measures of relative socioeconomic disadvantage. ${ }^{18}$ IRSD takes into account a range of variables including education, employment and financial

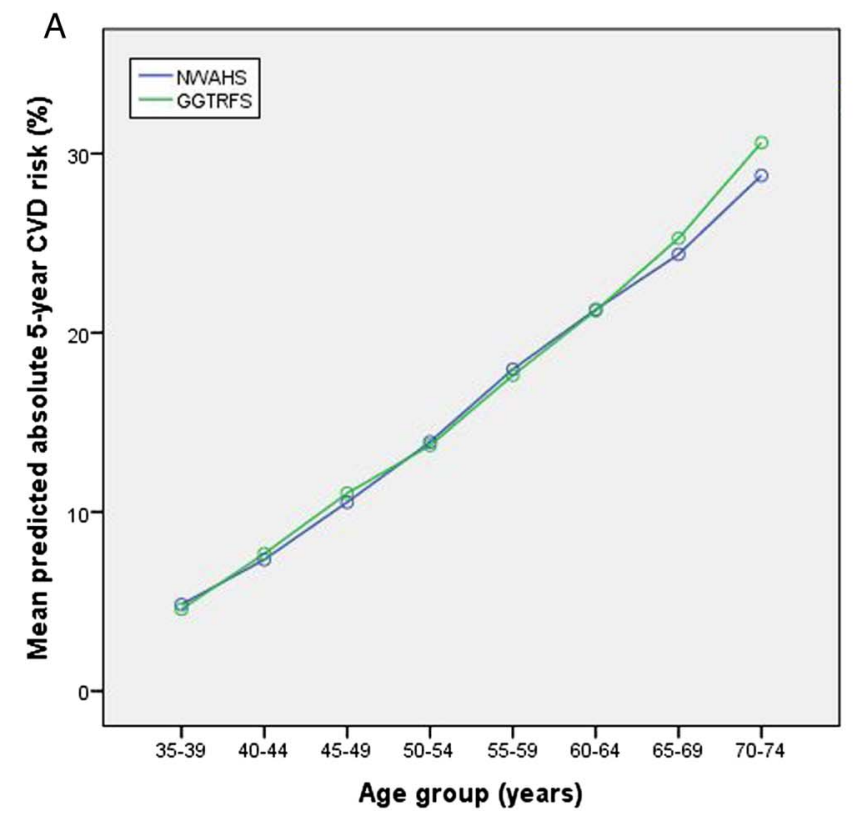

well-being. Although area and individual-level SES may have independent effects on health outcomes, only arealevel SES was taken into account.

The distribution of IRSD scores between GGT and NWA SLAs were compared and the relationship between IRSD and CVD mortality rates explored.

\section{Analyses}

Statistical analyses were undertaken using Stata V.12 and IBM SPSS Statistics V.19. CVD risk factor data for participants are reported as mean values with SEs for continuous variables and proportions with $95 \%$ CIs (using the Agresti-Coull technique) for discrete variables. Independent sample $t$ tests were used to assess differences between means $(\alpha=0.05)$, with the Welsch method applied when the assumption of homogenous variance was not met. The $\chi^{2}$ tests were used to assess differences between proportions $(\alpha=0.05)$. The relationship between mortality rates and IRSD scores was examined using linear regression.

\section{RESULTS}

Demographic characteristics of participants

NWAHS participants were younger, more diverse in their country of origin, more likely to be single, separated or divorced and less likely to be in part-time or casual employment than GGT RFS participants (table 1).

\section{Comparing measures of CVD risk}

Framingham 5-year absolute CVD risk scores were not significantly different between GGT RFS and NWAHS participants (age-specific groups and overall, figure 1A).

There were some differences in individual CVD risk factors after standardising to the 2006 Australian population but the magnitude of differences were small (table 2). NWAHS participants had a lower mean systolic blood

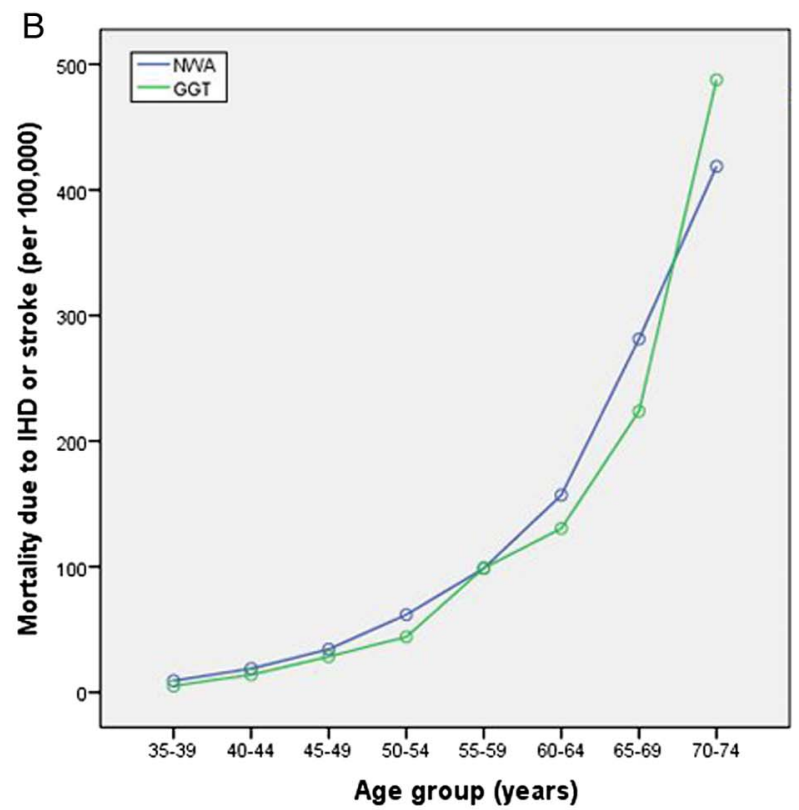

Figure 1 (A) Framingham absolute cardiovascular diseaserisk and (B) ischaemic heart disease and stroke mortality rates by age. 
pressure and higher mean diastolic blood pressure than GGT RFS participants. High-density lipoprotein (HDL) cholesterol was lower in NWAHS (men and overall). Total triglycerides were higher in NWAHS overall (though not quite reaching statistical significance), yet lower in NWA women. NWA men had higher body mass index (BMI) and waist circumference. NWAHS participants (women and overall) were more likely to be smokers. Prevalence of diabetes/impaired glucose tolerance (IGT) was higher in NWAHS (men and overall).

\section{Comparing CVD mortality outcomes}

Figure 1B shows the relationship between IHD and stroke mortality and age for GGT and NWA. Table 3 compares IHD and stroke mortality rates among different regions of interest. IHD and stroke mortality in inner and outer regional areas was generally worse than in major cities $(p<0.001)$. Remote and very remote areas had significantly higher mortality rates than all other categories $(p<0.001)$.

In all age groups, GGT mortality rates were representative of those of inner and outer regional areas (crude mortality rates for 35-74 years: inner and outer regional vs GGT 92 vs $98, p=0.341)$. NWA mortality was generally higher than in other major Australian cities (crude mortality rates for 35-74 years: major cities vs NWA 70 vs 103, $\mathrm{p}=0.028$ ). GGT and NWA mortality rates did not differ significantly despite NWA being a major city location (crude mortality rates for 35-74 years: GGT vs NWA $\mathrm{p}=0.489$ ).

Table 2 Individual CVD risk factor data by location

\begin{tabular}{|c|c|c|c|c|c|c|c|}
\hline & \multicolumn{3}{|c|}{ NWAHS mean (SE, N) } & \multicolumn{3}{|c|}{ GGT RFS mean (SE, N) } & p Value \\
\hline Mean systolic blood pressure $(\mathrm{mmHg})$ & \multicolumn{3}{|c|}{$123.37(0.31,2639)$} & \multicolumn{3}{|c|}{$126.00(0.48,1419)$} & $<0.001$ \\
\hline Men & \multicolumn{3}{|c|}{$126.71(0.43,1302)$} & \multicolumn{3}{|c|}{$128.60(0.64,700)$} & 0.014 \\
\hline Women & \multicolumn{3}{|c|}{$120.12(0.44,1337)$} & \multicolumn{3}{|c|}{$123.47(0.69,719)$} & $<0.001$ \\
\hline Mean diastolic blood pressure $(\mathrm{mm} \mathrm{Hg})$ & \multicolumn{3}{|c|}{$80.55(0.20,2639)$} & \multicolumn{3}{|c|}{$76.06(0.29,1418)$} & $<0.001$ \\
\hline Men & \multicolumn{3}{|c|}{$83.80(0.26,1302)$} & \multicolumn{3}{|c|}{$79.27(0.40,700)$} & $<0.001$ \\
\hline Women & \multicolumn{3}{|c|}{$77.39(0.26,1337)$} & \multicolumn{3}{|c|}{$72.93(0.39,718)$} & $<0.001$ \\
\hline Total cholesterol (mmol/L) & \multicolumn{3}{|c|}{$5.37(0.02,2647)$} & \multicolumn{3}{|c|}{$5.37(0.03,1377)$} & 0.903 \\
\hline Men & \multicolumn{3}{|c|}{$5.38(0.03,1299)$} & \multicolumn{3}{|c|}{$5.39(0.04,680)$} & 0.887 \\
\hline Women & \multicolumn{3}{|c|}{$5.36(0.03,1348)$} & \multicolumn{3}{|c|}{$5.34(0.04,697)$} & 0.742 \\
\hline LDL cholesterol (mmol/L) & \multicolumn{3}{|c|}{$3.26(0.02,2554)$} & \multicolumn{3}{|c|}{$3.22(0.03,1353)$} & 0.171 \\
\hline Men & \multicolumn{3}{|c|}{$3.31(0.03,1221)$} & \multicolumn{3}{|c|}{$3.30(0.04,658)$} & 0.852 \\
\hline Women & \multicolumn{3}{|c|}{$3.22(0.02,1333)$} & \multicolumn{3}{|c|}{$3.14(0.04,694)$} & 0.071 \\
\hline HDL cholesterol (mmol/L) & $1.43(0$ & $.01,2647)$ & & $1.46(0$ & $.01,1377)$ & & 0.003 \\
\hline Men & $1.28(0$ & $.01,1299)$ & & $1.33(0$ & $.01,680)$ & & 0.001 \\
\hline Women & $1.56(0$ & $.01,1348)$ & & $1.59(0$ & $.01,697)$ & & 0.148 \\
\hline Total-C/HDL-C ratio & $3.97(0$ & $.02,2647)$ & & $3.93(0$ & $.04,1377)$ & & 0.328 \\
\hline Men & $4.38(0$ & $.03,1299)$ & & $4.31(0$ & $.06,680)$ & & 0.298 \\
\hline Women & $3.58(0$ & $.03,1348)$ & & $3.56(0$ & $.04,697)$ & & 0.657 \\
\hline LDL-C/HDL-C ratio & $2.40(0$ & $.02,2554)$ & & $2.37(0$ & $.03,1353)$ & & 0.388 \\
\hline Men & $2.66(0$ & $.02,1221)$ & & $2.63(0$ & $.04,658)$ & & 0.585 \\
\hline Women & $2.16(0$ & $.02,1333)$ & & $2.13(0$ & $.03,694)$ & & 0.351 \\
\hline Total triglycerides (mmol/L) & $1.55(0$ & $.03,2647)$ & & $1.48(0$ & $.03,1322)$ & & $0.065^{*}$ \\
\hline Men & $1.83(0$ & $.05,1299)$ & & $1.64(0$ & $.04,650)$ & & $0.262^{*}$ \\
\hline Women & $1.28(0$ & $.03,1348)$ & & $1.33(0$ & $.03,673)$ & & $<0.001^{*}$ \\
\hline BMI $\left(\mathrm{kg} / \mathrm{m}^{2}\right)$ & 28.30 & $0.11,2658)$ & & 28.00 & $0.15,1413)$ & & 0.089 \\
\hline Men & 28.51 & $0.14,1308)$ & & 28.05 & $0.18,699)$ & & 0.043 \\
\hline Women & 28.09 & $0.17,1349)$ & & 27.92( & $0.23,714)$ & & 0.545 \\
\hline Waist circumference (cm) & & & & & & & \\
\hline Men & 99.77( & $0.38,1302)$ & & 97.85( & $0.48,695)$ & & 0.002 \\
\hline Women & 87.71 & $0.39,1337)$ & & 88.07( & $0.55,714)$ & & 0.587 \\
\hline & $\%$, & $95 \% \mathrm{Cl}$ & (n) & $\%$, & $95 \% \mathrm{Cl}$ & (n) & \\
\hline Current smokers & 21.35, & 19.83 to 22.95 & (2642) & 17.79, & 15.88 to 19.88 & (1405) & 0.028 \\
\hline Men & 22.75, & 20.55 to 25.11 & (1301) & 20.26, & 17.44 to 23.41 & (696) & 0.302 \\
\hline Women & 19.99, & 17.93 to 22.21 & (1341) & 15.37, & 12.90 to 18.22 & (709) & 0.032 \\
\hline Known diabetes or Impaired Glucose Tolerance & 7.72 & 6.76 to 8.80 & (2656) & 5.84 & 4.73 to 7.18 & (1422) & 0.037 \\
\hline Men & 8.34, & 6.96 to 9.97 & $(1307)$ & 5.14, & 3.72 to 7.06 & $(700)$ & 0.014 \\
\hline Women & 7.19, & 5.92 to 8.69 & $(1350)$ & 6.38 & 4.80 to 8.42 & (721) & 0.520 \\
\hline
\end{tabular}

The weighting of the data can result in rounding discrepancies or totals not adding.

${ }^{*} p$ Values based on log of the variable in order to address right skewedness of data.

Bold indicates significant $p$ values.

BMI, body mass index; CVD, cardiovascular disease; GGT RFS, Greater Green Triangle Risk Factor Study; HDL, high-density lipoprotein; IGT, impaired glucose tolerance; LDL, low-density lipoprotein;NWAHS, North West Adelaide Health Study. 


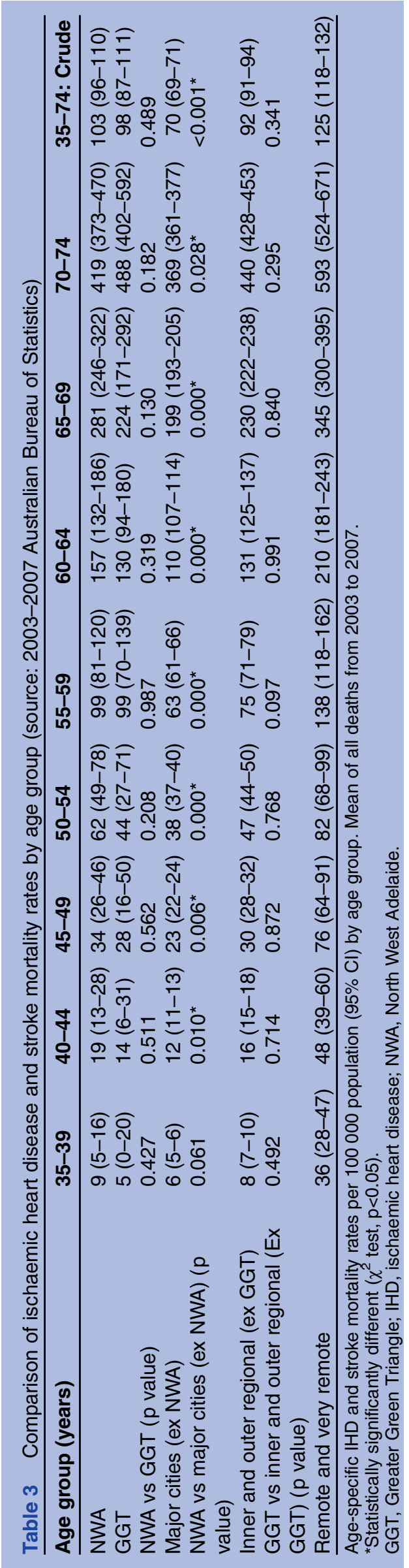

Relationship between SES and CVD mortality rates

A comparison of IRSD scores using an independent samples median test indicated no significant difference between the two study areas $(\mathrm{p}=0.108)$. However, there was a significant difference in the distribution of IRSD scores $(p=0.022)$, with scores in NWA skewed towards the lower end of the scale (figure 2A).

Increasing mortality was consistently associated with lower IRSD scores. When age-specific mortality rates for age class 35-74 were plotted against IRSD (figure 2B), both study areas were most closely aligned with inner and outer regional areas. Closer inspection of study areas at the SLA level indicated that the trend remained. In NWA (figure 2C) IRSD explained around $46 \%(n=18$, $\beta=-0.389$ ) of the variation in mortality. In GGT (figure 2D) IRSD explained approximately $19 \% \quad(\mathrm{n}=13$, $\beta=-0.477$ ) of the variation in mortality, although the relationship was not statistically significant.

\section{DISCUSSION}

Geographic and socioeconomic disparities in CVD mortality were first described in Australia in the late 1990s, ${ }^{19}$ and initiated debate about likely explanations. Socioeconomic and cultural diversity among regions, differential prevalence of CVD risk factors and variations in patterns of medical care were postulated as potential causative factors. This work initiated a debate about the most appropriate actions to be undertaken both within and outside the healthcare system to address these disparities. ${ }^{20} 21$ Progress since has been slow in advancing our understanding of these issues, impeded by the lack of comprehensive, high-quality data on CVD risk factor prevalence across the Australian population.

On the basis of AIHW published data, ${ }^{3} 46$ and the only previous Australian study to analyse the contribution of CVD risk factor prevalence differences to the rural/regional-urban CVD mortality gap, ${ }^{22}$ our original hypothesis in this study was that GGT CVD risk factor profiles, and CVD mortality, would be worse than in NWA. Unexpectedly, GGT and NWA were similar in terms of absolute CVD risk scores, individual CVD risk factors and mortality rates. Furthermore, mortality rates in the regional GGT population are consistent with those observed in most regional areas of Australia, but lower than in remote areas, and higher than in the overall Australian metropolitan population. CVD mortality rates in the metropolitan NWA population are significantly higher than in the overall Australian metropolitan population.

Social gradients in health-'caused by unequal distribution of power, income, goods and services' lead to inequitable health outcomes within and between populations. ${ }^{1}$ Poorer Australians have worse CVD outcomes. ${ }^{23}$ This was demonstrated in our study by the strong relationship between IRSD and CVD mortality at a national level (figure 2B) as well as within NWA (figure 2C). The trend was present within GGT (figure 2D), although 

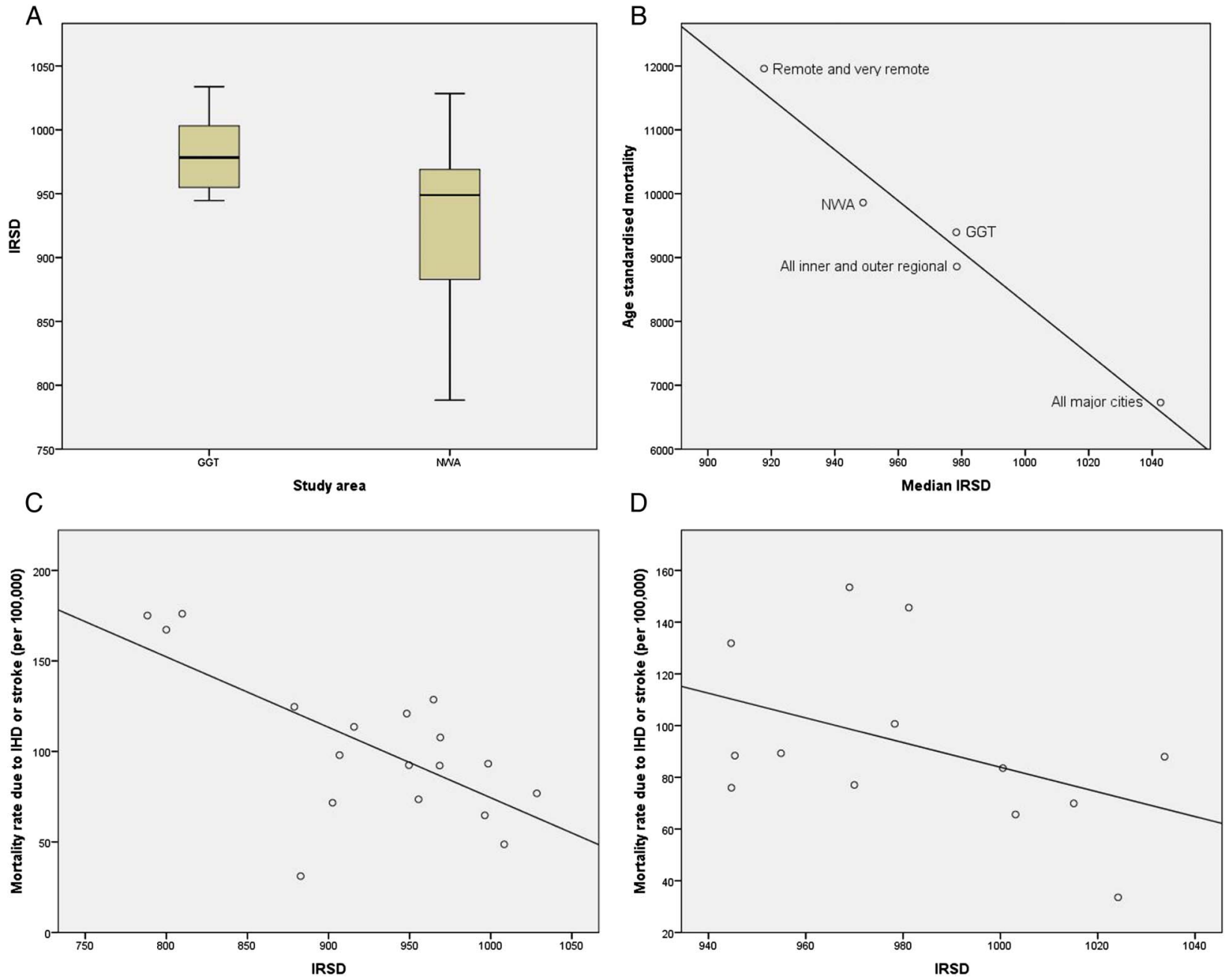

Figure 2 Relationship between ischaemic heart disease (IHD) and stroke mortality and IRSD. (A) Distribution of Index of Relative Socioeconomic Disadvantage (IRSD) scores between greater green triangle (GGT) and north west Adelaide (NWA); (B) IHD and stroke mortality rates by median IRSD for relevant geographical areas; (C) IHD and stroke mortality rates by IRSD for NWA statistical local area (SLAs); (D) IHD and stroke mortality rates by IRSD for GGT SLAs.

statistically non-significant. This can likely be explained by limited sample size coupled with a relatively narrow range of IRSD scores compared with NWA. These findings are consistent with other evidence in the Australian literature and from other developed countries regarding the association among low SES and increased levels of CVD risk factors, morbidity and mortality. ${ }^{21}$

The influence of a broad range of social determinants (eg, quality of housing, employment, income level, education, etc) on biological determinants of CVD, as well as differential access to health-promoting services may explain a significant part of the rural/regional-urban divide in CVD mortality in Australia. There is also growing evidence that variation in implementation of evidence-based CVD care across geographic, institutional and even subspecialty boundaries may be an important determinant. $^{24} 25$ Implementation of evidence-based practice may provide an opportunity to reduce disparities in CVD outcomes, including geographically determined disparities, at relatively low cost and in shorter time frames than those required to address socioeconomic disparities across large populations.

All of the aforementioned variables and their relationship with CVD health outcomes are complex, yet all should be taken into account when formulating strategies to address inequalities.

Our study has limitations. First, there are difficulties in extrapolating results from single rural and urban populations. This regional study population is relatively culturally and socioeconomically homogenous and probably representative of many (but not all) regional areas in Australia. The urban population is more culturally and socioeconomically diverse with overrepresentation of the socioeconomically disadvantaged compared with the overall Australian urban population. Second, we were unable to directly analyse associations among risk factors, SES and CVD mortality in the sample data sets due to the cross-sectional rather than longitudinal design of the two population-based risk factor studies and other methodological differences in sampling and 
data collection. Time frames influencing some crosssectional measured risk factor variables, compared with those operating over whole lifetimes to determine clinical outcomes such as CVD mortality, are different and we cannot be sure whether they are stable or changing at the same rate in two geographically distinct populations. Some such variables which were not measured in our study, such as population levels of salt intake, may have resulted in the difference in systolic and diastolic blood pressures in our two study groups. However, we think that the most likely explanation for this observation is interobserver variation in the measurement of blood pressure.

Strategies for comprehensive, high-quality CVD risk factor surveillance should cover all population groups, regardless of geography or SES. Preferably, there should be longitudinal follow-up, combined with appropriate epidemiological and health services research to investigate which interventions are most able to cost-effectively reduce disparities in CVD outcomes in the specific context of each of our social and healthcare systems.

\author{
Author affiliations \\ ${ }^{1}$ Integrated Cardiovascular Clinical Network, Country Health SA Local Health \\ Network, Flinders Medical Centre, Adelaide, Australia \\ ${ }^{2}$ Population Research and Outcome Studies, The University of Adelaide, \\ Australia \\ ${ }^{3}$ Department of Medicine, NorthWest Academic Centre, The University of \\ Melbourne, Western Hospital, Melbourne, Australia \\ ${ }^{4}$ Greater Green Triangle University Department of Rural Health, Flinders and \\ Deakin Universities, Warrnambool, Victoria, Australia \\ ${ }^{5}$ Queensland University of Technology, Brisbane, Australia \\ ${ }^{6}$ National Institute for Health and Welfare, Helsinki, Finland \\ ${ }^{7}$ Institute of Public Health and Clinical Nutrition, University of Eastern Finland, \\ Kuopio, Finland \\ ${ }^{8}$ Integrated Cardiovascular Clinical Network, Country Health SA Local Health \\ Network, Adelaide, Australia
}

Acknowledgements The investigators are most grateful to study participants, recruiting and research support staff for their substantial contribution to the success of the study. Special thanks to Sami Heistaro for coordination and supervision of data collection for the GGT study and Sandra Pickering for the NWAHS study.

Contributors PT conceived and designed the study. AT, RC, AM, JG and JAD were involved in acquisition of data. BP, EJ, EP and VV analysed and interpreted the data. EP and EJ drafted the manuscript and were responsible for its revisions. VV and RC helped to draft the manuscript. All authors contributed to specific sections in the manuscript. All authors read and approved the final manuscript.

Funding Funders of the GGT RFS and NWAHS studies included Flinders Medical Centre, the Royal Australian College of General Practitioners, sanofi-aventis PL, Pfizer Inc, Roche Diagnostics, Servier Laboratories Australia PL, the University of Adelaide, the South Australian Department of Health and the Australian Government Department of Health and Ageing, Canberra.

Competing interests PT received an AHMAC Capacity Building Grant for Health of Populations (PDR01/14) and a grant from Pfizer. R Clark is funded by a Postdoctoral Research Fellowship supported by the National Health and Medical Research Council (NHMRC-APP 570 141). EJ received a $\$ 20000$ grant to carry out the Wimmera Shire part of GGT risk factor prevalence study. AT is Epidemiological Principal Investigator of the North West Adelaide Health Study. JAD was the chief investigator for the GGT DPP.

Ethics approval Ethics approval for GGT RFS was obtained from the Flinders Clinical Research Ethics Committee, Adelaide, approval number 207/034. Approval for NWAHS stage 2 was obtained from The Queen Elizabeth Hospital
(TQEH) Human Research Ethics Committee (HREC), Adelaide, approval number 2004030. HREC approval for comparison analysis was given by the University of South Australia, Adelaide, and the Queensland University of Technology, Brisbane, approval numbers P136/09 and 1000000988.

Provenance and peer review Not commissioned; externally peer reviewed.

Data sharing statement No additional unpublished data are publicly available - for further information please contact Prof James Dunbar at director@greaterhealth.org and Janet Grant at janet.grant@adelaide.edu.au.

Open Access This is an Open Access article distributed in accordance with the Creative Commons Attribution Non Commercial (CC BY-NC 3.0) license, which permits others to distribute, remix, adapt, build upon this work noncommercially, and license their derivative works on different terms, provided the original work is properly cited and the use is non-commercial. See: http:// creativecommons.org/licenses/by-nc/3.0/

\section{REFERENCES}

1. Commission on the Social Determinants of Health (CSDH). Closing the gap in a generation: health equity through action on the social determinants of health. Final Report of the Commission on Social Determinants of Health. World Health Organization, 2008. http:// www.who.int/social_determinants/thecommission/finalreport/en/ index.html (accessed Dec 2012).

2. Australian Bureau of Statistics. 2012 Year Book Australia (ABS Cat. No 1301.0). Canberra: ABS, 2012. http://www.abs.gov.au/ausstats/ abs@.nsf/Lookup/by\%20Subject/1301.0 2012 Main\% 20Features Downloads 96 (accessed May 2012).

3. Australian Institute of Health and Welfare. Rural, regional and remote health: Indicators of health status and determinants of health (AlHW Cat. No. PHE 97). Canberra: AlHW, 2008. http://www.aihw.gov.au/ publication-detail/?id=6442468076 (accessed May 2012).

4. Australian Institute of Health and Welfare. Australia's health 2010 (AlHW Cat. No. AUS 122). Canberra: AlHW, 2010. http://www.aihw. gov.au/publication-detail/?id=6442468376\&tab=2 (accessed May 2012).

5. Australian Bureau of Statistics. 2010 causes of death, Australia (ABS Cat. No. 3303.0). Canberra: ABS, 2012. http://www.abs.gov.au/ AUSSTATS/abs@.nst/DetailsPage/3303.02010?OpenDocument (accessed Dec 2012).

6. Australian Institute of Health and Welfare. Risk factors contributing to chronic disease (AlHW Cat. No. PHE 157). Canberra: AlHW, 2012. http://www.aihw.gov.au/publication-detail/?id=10737421466\&tab=2 (accessed May 2012).

7. Janus ED, Laatikainen T, Dunbar JA, et al. Overweight, obesity and metabolic syndrome in rural southeastern Australia. Med $J$ Aust 2007;187:147-52.

8. Janus ED, Tideman PA, Dunbar JA, et al. Dyslipidaemia in rural Australia: prevalence, awareness, and adherence to treatment guidelines in the Greater Green Triangle Risk Factor Study. Med J Aust 2010;192:127-32.

9. Janus ED, Bunker SJ, Kilkkinen A, et al. Prevalence, detection and drug treatment of hypertension in a rural Australian population: the Greater Green Triangle Risk Factor Study 2004-2006. Intern Med J 2008;38:879-86.

10. Grant JF, Taylor AW, Ruffin RE, et al. Cohort profile: the North West Adelaide Health Study (NWAHS). Int J Epidemiol 2009;38:1479-86.

11. Grant JF, Chittleborough CR, Taylor AW, et al. The North West Adelaide Health Study: detailed methods and baseline segmentation of a cohort for selected chronic diseases. Epidemiol Perspect Innov 2006;3:4-14.

12. Australian Bureau of Statistics. SA Stats (ABS Cat. No. 1345.4.). Canberra: ABS, 2011. http://www.abs.gov.au/ausstats/abs@.nst/mf/ 1345.4 (accessed Aug 2012)

13. Taylor AW, Dal Grande E, Gill T, et al. Do people with risky behaviours participate in biomedical cohort studies? BMC Public Health 2006;6:1-8.

14. Montgomerie A, Tideman P, Taylor A, et al. An epidemiological analysis of risk factors: rural versus metropolitan-are there differences? Adelaide: Population Research \& Outcome Studies Unit - SA Health; and Greater Green Triangle, University Department of Rural Health, Flinders University and Deakin University 2010. http:// www.greaterhealth.org (accessed Jun 2012).

15. National Vascular Disease Prevention Alliance. Absolute cardiovascular disease risk. Technical report: review of the evidence and evidence-based recommendations for practice. National Heart Foundation of Australia; 2009. http://www.heartfoundation.org.au/ 
SiteCollectionDocuments/Absolute-risk-technical-report.pdf (accessed Aug 2012).

16. Australian Bureau of Statistics. Population estimates: concepts, sources and methods (ABS Cat. No. 3228.0.55.001). Canberra: ABS, 2009. http://www.abs.gov.au/AUSSTATS/abs@.nsf/ DetailsPage/3228.0.55.0012009?OpenDocument\#Publications (accessed Dec 2012).

17. Australian Bureau of Statistics. Australian Standard Geographical Classification (ABS Cat No. 1216.0). Canberra: ABS, 2010. http:// www.abs.gov.au/AUSSTATS/abs@.nsf/DetailsPage/1216.0July\% 202010?OpenDocument (accessed Dec 2012).

18. Australian Bureau of Statistics. Information Paper: An Introduction to Socio-Economic Indexes for Areas (ABS Cat. No. 2039.0). Canberra: ABS, 2006. http://www.abs.gov.au/AUSSTATS/abs@.nsf/ DetailsPage/2039.02006?OpenDocument (accessed Dec 2012).

19. Sexton PT, Sexton T-LH. Excess coronary mortality among Australian men and women living outside the capital city statistical divisions. Med J Aust 2000;172:370-4.
20. Heller RF. Mortality from cardiovascular disease is too high outside capital cities. Med J Aust 2000;172:360-1.

21. Tonkin AM, Pope J, Glover JD. Ischaemic heart disease: across the social and geographic divides. Med J Aust 2000;173:173-4.

22. Thomson A, Rundle S, Singh BB, et al. Regional differences in cardiovascular risk factor prevalence in Tasmania: are they consistent with the increased cardiovascular mortality? Aust $N Z \mathrm{~J}$ Med 1995;25:290-6.

23. Begg S, Vos T, Barker B, et al. The burden of disease and injury in Australia 2003 (AlHW Cat. No PHE 82). Canberra: AlHW, 2007. http://www.aihw.gov.au/search/?q=The+burden+of+disease+and +injury+in+Australia+2003 (accessed Jun 2012).

24. Lim L, O'Connell R, Heller R. Differences in management of heart attack patients between metropolitan and regional hospitals in the Hunter Region of Australia. Aust N Z J Public Health 1999;23:61-6.

25. Lim L, Heller R, O'Connell R, et al. Stated and actual management of acute myocardial infarction among different specialities. Med $J$ Aust 2000;172:208-12. 


\section{Correction}

Tideman P, Taylor A, Janus E, et al. A comparison of Australian rural and metropolitan cardiovascular risk and mortality: the Greater Green Triangle and North West Adelaide Population Surveys. BMJ Open 2013;3:e003203. An error in the coding of one of the categorical variables used to calculate the Framingham five-year risk was detected following publication. The error does not affect the overall conclusions drawn in this paper but has changed figure 1A. The corrected figure $1 \mathrm{~A}$ is below.

In addition, the first sentence of the Results section of the Abstract should now read: 'Few significant differences in CVD risk between the study regions, with mean absolute CVD risk ranging from approximately $1 \%$ in the age group $35-39$ years to $14 \%$ in the age group $70-74$ years.'

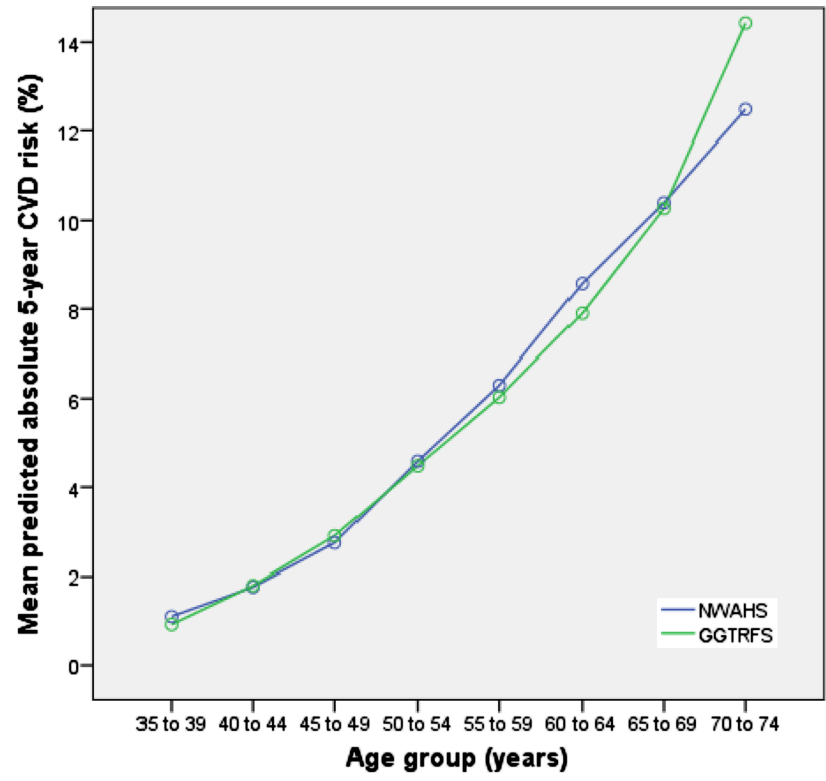

Figure 1A Framingham absolute cardiovascular disease risk by age.

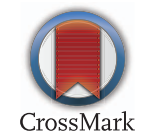

BMJ Open 2014;4:e003203corr1. doi:10.1136/bmjopen-2013-003203corr1 